\title{
Research on the Characteristics and Realization Path of "Four Histories" Education from the Perspective of "Three Complete Education" in Colleges and Universities
}

\author{
Wang Bingbing ${ }^{1}, \mathrm{Li} \mathrm{Xin}^{2, *}$ \\ ${ }^{1}$ School of Chemical and Environmental Engineering, Anhui Polytechnic University, Wuhu, China \\ ${ }^{2}$ School of Mechanical Engineering, Anhui Polytechnic University, Wuhu, China \\ Email address: \\ 496707874@qq.com (Wang Bingbing), lx600526@126.com (Li Xin) \\ ${ }^{*}$ Corresponding author
}

To cite this article:

Wang Bingbing, Li Xin. Research on the Characteristics and Realization Path of "Four Histories" Education from the Perspective of "Three Complete Education" in Colleges and Universities. Science Innovation. Vol. 9, No. 4, 2021, pp. 151-155. doi: 10.11648/j.si.20210904.16

Received: April 16, 2021; Accepted: June 3, 2021; Published: June 4, 2021

\begin{abstract}
In recent years, the "four histories" education has been introduced into the ideological and political education in Colleges and universities, which integrates the history of the party, the history of new China, the history of reform and opening up and the history of socialist development into the content of students' ideological and political education. It is in line with the requirements of patriotism in the new era. The "three complete education" is an effective education mode in the ideological and political education in Colleges and universities. This paper firstly explains the importance of the combination of "four histories" education and three complete education mode in Colleges and universities, analyzes the characteristics of "four histories" education from the perspective of three complete education, and finally gives the realization path of "four histories" education from the perspective of three complete education. The "four histories" education based on the three complete education mode in Colleges and universities is a new mode to carry out the "four histories" education in Colleges and universities. Through the research of this paper, we can provide new ideas for the extensive development of this new mode in the "four histories" Education in Colleges and universities.
\end{abstract}

Keywords: "Four Histories" Education, Ideological And Political Curriculum, Three Complete Education, Realization Path

\section{高校三全育人视域下“四史”教育的特征及实现路径探究}

\author{
${\text { 王冰冰 }{ }^{1} \text {, 李金唋 }}^{*}$ \\ 1安徽工程大学化学与环境工程学院, 芜湖, 中国 \\ 2安徽工程大学机械工程学院, 芜湖, 中国
}

\section{邮箱}

496707874@qq.com（王冰冰）,1x600526@126.com（李金金）

摘要: 近年来, 高校思政课程引入“四史”教育, 将党史、新中国史、改革开放史和社会主义发展史融入到学生思政教 育内容中，符合新时代爱国主义要求，三全育人是高校思政教育中有效的教育模式。本文首先阐释了高校“四史”教育 与三全育人模式结合的重要性, 分析了三全育人视域下的“四史”教育特征, 最后给出了高校三全育人视域下“四史”教 育的实现路径。基于高校三全育人模式的“四史”教育, 是高校开展“四史”教育的新模式, 通过本文的研究, 能够为这 种新模式在高校“四史”教育中的广泛开展提供新的思路。 
关键词: “四史”教育, 思政课程, 三全育人, 实现路径

\section{1. 引言}

2020年，习总书记在“不忘初心、牢记使命”主题教育 总结大会上强调: “要把学习贯彻党的创新理论作为思想 武装的重中之重, 同学习马克思主义基本原理贯通起来, 同学习党史、新中国史、改革开放史、社会主义发展史结 合起来。”[1]强调“重视历史、研究历史、借鉴历史是中华 民族5000多年文明史的一个优良传统。”[2]在高校思政课 程开展“四史”教育, 符合新时代爱国主义教育的要求, 也 是高校思政课程改革创新面临的新机遇。在全国高校思想 政治工作会议上, 习近平总书记指出: “高校思想政治工 作关系高校培养什么样的人、如何培养人以及为谁培养人 这个根本问题。要坚持把立德树人作为中心环节, 把思想 政治工作贯穿教育教学全过程, 实现全员育人、全过程育 人、全方位育人，努力开创我国高等教育事业发展新局 面。”[3]这一论断强调了三全育人在思政教育中的重要地 位, 为高校三全育人的开展奠定了理论基础 [4-8]。

在当下高校思政教育中, 将“四史”教育与三全育人相 结合的教育模式并不多见，常见的文献资料多强调“四史” 教育在高校思政教育中的重要性，方涛[9]探析了“四史” 教育在高校思政课实践教学中的实现路径, 给出了通过 “三个结合”开展“四史”教育的具体措施，但是这些具体措 都是从“四史”教育的内容出发，并没有探索“四史”教育与 三全育人模式结合的效果。戴海容 [10]分析了高职院校“四 史”教育的实现路径，他认为在进行高职院校“四史”教育 中, 精准施教是关键, 聚焦于教育过程的某些环节, 对于 教育的全过程、全方位并没有太多关注。王玉[11]同样分 析了高校“四史”教育的实现路径，他从“四史”教育的内容 角度提出, 要注重“四史”教育的整体性, 并未关注教育方 式的实现。

鉴于以上分析，本文将从高校三全育人视域下的“四 史”教育着手, 剖析其特征, 并对高校三全育人视域下的 “四史”教育实现路径开展探究, 为高校“四史”教育提供新 的参考模式。

\section{2. 高校“四史”教育与三全育人结合的重要性}

\section{1. 创新教育模式, 推动高校“四史”教育全局建设}

当前, “毛概”、“邓论”等课程已进入高校思政课程体 系，虽没有明确设置“四史”教育课程，但“四史”教育内容 与现有的思政课程体系各教学内容息息相关。如果脱离社 会主义发展史, 就无法谈理想信念; 如果不学习党史和新 中国发展史, 就无法明确爱国主义核心; 如果不接触改革 开放史, 就不能深入领会时代精神。所以, “四史”教育是 贯穿高校思政课程的重要教学内容, 强化“四史”教育对高 校思政课程建设具有时代意义。

多数高校“四史”教育模式中，教育方式以灌输为主， 教育主体以思政教师为主, 教育过程集中在思政课堂, 这
一教育模式在教育主体、教育时间与空间上都造成了局限, 基于三全育人的“四史”教育突破了这一局限性[12-15]。首 先，突破了教育主体的局限性，基于三全育人的“四史”教 育强调全员参与“四史”教育, 高校各岗位都应具有“四史” 教育功能和责任, 从而将教育主体从思政教师扩展到全体 教职工。其次, 突破了教育时间的局限性, 基于三全育人 的“四史”教育过程不仅在课堂, 更在学生的日常生活和学 习中, 实现“四史”教育过程无间断。最后, 突破了教育空 间的局限性，基于三全育人的“四史”教育突出多载体、多 渠道育人方式, 通过学校课堂、网络、社会实践等多维度 空间完成育人过程。而且, 三全育人思想构建了服务育人、 教书育人、管理育人的全方位格局, 为“四史”教育创造了 新的育人模式。基于三全育人的“四史”教育, 不但能够为 高校“四史”教育提供创新模式, 还能够促进高校“四史”教 育全面发展。

\section{2. 将中国特色社会主义思想深植学生头脑, 树立和培 养正确价值观念}

高校思政课程是学生掌握党的创新理论的主要路径, 需要“坚持思政课程建设与党的创新理论武装同步推进, 全面推动习近平新时代中国特色社会主义思想进教材、进 课堂、进学生头脑”。重中之重是要“进学生头脑”, 这不 意味着填鸭式的灌输, 而是要彻底学懂、弄通, 深刻领悟 党的创新理论核心要义, 把握贯穿理论的马克思主义原理, 通过了解其思想不断提高马克思主义理论水平。只有全面 了解“四史”, 学生才能真正理解习近平新时代中国特色社 会主义思想的本质。

基于三全育人的“四史”教育，能够发挥育人主体的主 观能动性, 帮助学生树立和培养正确价值观。首先, 基于 三全育人的“四史”教育可以调动全岗位合力发挥育人作 用, 高校教职工都参与“四史”教育, 服务、管理和教育环 节中的各个岗位共同担负学生价值观的培育责任。其次, 由于学生的价值观形成需要一定的过程, 并不是通过一两 门思政课就可以实现的，而基于三全育人的“四史”教育突 破了传统教育的时间尺度约束, 通过将正确的价值观贯穿 学生学习、生活中的时时刻刻, 以实现树人的持续性。最 后, 基于三全育人的“四史”教育还能够整合教育资源, 突 破课堂、学校的空间限制, 通过网络、社会实践等渠道多 维度地覆盖培养学生价值观的教育空间。因此, 基于三全 育人的“四史”教育能够高效地将中国特色社会主义思想 融入学生认知, 并树立正确的价值观。

\section{3. 高校三全育人视域下“四史”教育的特征}

\section{1. 全员参与, 育人过程持续而全面}

高校中基于三全育人的“四史”教育可以调动一切教 职工参与其中, 既丰富了“四史”教育的主体内涵, 又体现 了参与主体的广泛性。一方面, 基于三全育人的“四史”教 
育突出高校每一个教育主体的教育功能和责任, 作为高校 的每一位教职工都应该是“四史”教育的参与者, 极大地扩 大了“四史”教育育人的主体范围, 不仅丰富了育人主体内 涵, 还增加了育人主体的教育职责。另一方面, 基于三全 育人的“四史”教育也将社会成员及家庭成员纳入教育主 体范围, 进一步扩大了教育主体的覆盖面, 通过学校、家 庭和社会的三重教育使“四史”育人呈现多层次育人格局。 由于基于三全育人的“四史”教育对象是人，只有充分发挥 教育主体优势, 才能保证“四史”育人工作顺利开展。

高校中基于三全育人的“四史”教育要贯穿学生的学 习、生活全过程, 了解学生在每个阶段的特点, 针对其思 想发展规律开展“四史”教育, 体现了教育过程的持续性。 一方面, 基于三全育人的“四史”教育强调融入学生成长的 全过程, 从而保证育人工作的持续性。另一方面, 针对学 生在不同时期的思想演变规律, 结合实际, 对学生进行有 针对性的“四史”教育内容, 从而保证学生各个阶段的“四 史”教育内容能够有效衔接。

高校中基于三全育人的“四史”教育突出多载体、多渠 道的育人模式，体现了育人内涵的全面性。一方面，基于 三全育人的“四史”教育通过课堂授课、线上线下交互、社 会实践等渠道对学生开展“四史”教育, 实现多维度整合教 育资源, 拓展了“四史”教育的实现路径。另一方面, 基于 三全育人的“四史”教育不但将高校教职工囊括在内, 更把 家庭成员和社会成员纳入到教育主体范围内, 形成“四史” 育人全方位格局，拓宽了“四史”教育主体载体。

\section{2. 精确定位“四史”教育的整体性}

中国共产党的执政理论是马克思主义理论，由中国 共产党领导的新时代中国特色社会主义事业是社会主义 发展史的重要内容, 中国共产党从建国初期开始, 历经 70 余年探索符合中国国情的发展道路, 具有中国特色的 社会主义道路是中国共产党在改革开放的实践中蹚出来 的。无论是在革命时期、建设时期, 还是在改革时期, 中国共产党都坚持不解地夯实中华民族伟大复兴事业道 路上取得的各个成果, 真正实现中华民族从站起来、富 起来到强起来的伟大壮举。所以, “四史”教育的整体性 就是系统阐释中国共产党推进中国特色社会主义伟大事 业的内在逻辑。

进入新时代, 高校思政课程教育的一项重要目标就是 要摒除历史虚无主义的影响, 帮助大学生树立正确的历史 观。思政教育中, 对负面的历史观进行批判, 还需要树立 正确的历史观，也就是“破立结合”，“四史”教育能够完整 地展现中国共产党带领中华民族走向伟大复兴的历程, 学 生通过“四史”教育能够正视历史, 正视中国共产党取得的 伟大成就。另外, 随着自媒体、互联网等新兴信息传播渠 道的出现, 学生获取历史知识的方式呈离散化发展, 一些 学生容易沉迷于历史的某个片段, 导致影响对整个历史过 程的正确解读, “四史”教育从党史、新中国史、改革开放 史和社会主义发展史的全过程出发, 引导学生正确理解历 史演变过程, 同时, 历史思维和能力也得到了培养。

\section{4. 高校三全育人视域下“四史”教育的实现路径 探究}

\section{1. 凝聚岗位合力, 通过主题活动, 以史育人}

高校基于三全育人的“四史”教育中, 全体教职工是教 育主体, 要凝聚各岗位的合力, 为学生的“四史”教育保驾 护航。另外, 由于学生在不同年级, 思想成熟度也不相同, 所以, 不妨从组织架构和时间两个维度着手, 探索基于三 全育人的“四史”教育实现路径。

在组织架构层面, 首先, 以党委领导为核心, 根据学 校实际情况制定方案, 并将要求下达至学校各部门, 编制 “四史”教育职责说明书, 明确部门及个人职责。使学校在 党委的统一领导下, 形成“四史”教育的大格局。加强育人 监督, 建立“四史”教育工作评价机制, 将“四史”育人成果 纳入部门考核。恰当地运用激励机制, 为“四史”育人工作 助力。其次, 充分发挥教师的教育主体作用。强化教师的 育人信念, 使授课教师正确理解“四史”教育并不是为老师 增加负担, 相反地, 做好“四史”教育能够激发学生的学习 热情, 提高教师的授课效果。深入挖掘专业课中的“四史” 元素, 既能加深授课教师对所授专业课的理解, 也能为所 授课程开拓新的研究和讲授领域。提升教师自身的政治素 养和“四史”理论水平, 组织教师积极学习国家重要会议精 神和方针政策, 常态化开展“四史”理论学习, 扎实理论功 底, 真正做到思想上与时俱进。鼓励思政教师求学深造, 建立“四史”教育思政说课制度。再次, 发挥班主任、辅导 员的积极引导作用。日常生活中, 多与学生沟通交流, 了 解学生思想动态, 可以开展形式多样的“四史”教育主题班 会, 调动学生对于红色文化的兴趣。最后, 培育后勤人员 的育人功能。由于后勤人员知识水平有限, 需要开展对后 勤人员的育人知识培训，同时融入“四史”教育育人的基本 方法培训, 使后勤人员重新定位自身的角色, 树立自信, 加强责任感, 能够把“四史”教育体现在日常的工作中。

在时间层面上, 针对不同年级学生的思想特点, 可开 展不同形式的“四史”教育。大一学生一般学习新鲜事物的 激情较高, 可以通过课堂开展“四史”教育, 讲述“四史”中 通俗的故事, 或由学生自己学习并讲述“我学到的“四史” 故事”, 提升思政课堂的感染力。针对大二学生, 可开展“四 史”研学实践活动, 通过组织学生走访当地红色遗址、收 集革命历史故事等形式, 指导学生完成“四史”调研报告。 大三学生, 更注重理论与实践相结合的教育方式。可以设 立“四史”文化大讲堂, 邀请革命老人或者优秀教师做“四 史”相关的文化讲座, 让学生感同身受, 切身体会国家发 展的脉络。大四学生进入实习阶段, 可将实习内容与“四 史”教育相融合, 让学生在学习生产技能的同时深入对“四 史”文化的理解。针对不同学年的学生开展不同形式的“四 史”教育, 迎合了学生思想演变的规律, 并把“四史”教育 贯穿大学始终, 体现了三全育人的持续性特征。

\section{2. 关注教育衔接, 发挥线上资源优势}

基于三全育人的“四史”教育是持续的育人工作，在高 校中, 贯穿学生从入学到毕业的所有阶段。学生在校学习 的过程中, 思想也日趋变得成熟, “四史”教育应根据学生 
思想的演变因时施教, 在学生思想发展的关键节点要做好 “四史”教育的衔接。由于课时的限制, 学生在校接受“四 史”教育的时间非常有限，除去课堂学习时间，日常充斥 着许多零碎的闲散时间和周末两天的小假期, 学期结束后, 学生还会迎来寒、暑假两个长假期, 即使学生在课堂上接 受了足够多的“四史”教育，被长、短假期的“放松”、“自娱 自乐”冲击后, “四史”教育的成果也所剩无几。因此, 要 增强学生的假期教育, 学校可以开办“四史”研习社团等, 鼓励学生利用课余及周末时间聚集在一起开展学习, 并制 定学分制度, 可把“四史”学习成果纳入奖学金评定机制中。 还可在周末公映红色电影, 以学生喜闻乐见的形式开展 “四史”教育, 不但满足学生想“放松”的心态, 还能在潜移 默化中加强“四史”教育效果。在学期期末临近结束时, 班 主任或辅导员可给学生布置假期社会实践作业, 通过收集 红色故事、走访红色遗迹等形式完成“四史”教育的相关调 研报告, 并制定评分标准, 可将学习成果纳入奖学金评定、 毕业评优等评价机制中, 引起学生对“四史”教育的重视, 还能避免学生在长假期出现无所事事的现象。

随着互联网的发展和融媒体的出现, 线上资源也能在 “四史”教育中发挥独特作用。在学生课余时间可定期发布 “四史”教育的相关学习资料, 鼓励学生养成自学习惯, 在 课堂教学中也可适当插入线上教学资源, 丰富“四史”教学 内容。在长假期中, 可在平台建立学习小组, 实行打卡监 督机制, 保证学生对“四史”内容的学习量。也可建立奖励 办法, 对“四史”学习成果突出的同学给予纪念品等奖励。

\section{3. 健全做强师资队伍, 形成以学校育人为主、家庭社 会育人为辅的格局}

当前, 高校普遍存在的问题是, 部分思政课程教师的 知识结构和专业素养难以承担“四史”教育工作，要将“四 史”教育顺利地在高校开展, 强有力的师资队伍不可缺少。 思政课程教师要投入更多精力提升专业技能, 积极参与 “四史”教育相关培训。此外，学校还应当促进“四史”教育 与其它专业课程的融合, 针对融入“四史”元素的专业课寻 求新的授课方式, 并推进“四史”教育的理论与实践相结合。 学校还要打造独特的“四史”文化氛围, 加强校风、学风建 设，充分利用网络资源深化“四史”教育成果。

社会对“四史”教育也有着不可忽视的作用，应积极打 造注重学生德智均衡发展的环境, 坚持践行社会主义核心 价值观, 为学生营造良好的育人氛围, 增强“四史”教育, 乃至思政教育的社会认同。

家庭作为学生“四史”教育的校外课堂, 也是引导学生 思政发展的重要组成部分。首先要转变家长的思想观念, 孩子进入大学后并不意味着家庭教育的结束, 应使家长充 分认识到, 通过“四史”教育为孩子树立正确的价值观, 是 能够影响孩子一生的大事。其次, 建立良好的家风, 能够 在潜移默化中育人, 为孩子的思想道德观念营造良好的环 境。

通过学校、社会、家庭的多元协同, 能够给学生创造 良好的“四史”教育环境, 这也是基于三全育人的“四史”教 育重要保证。

\section{5. 结论}

“四史”教育是当代高校思政教育课程中的主流教育 内容, 充分学习党史、新中国史、改革开放史和社会主义 发展史, 对增强学生民族自豪感及对中华民族的认同感具 有重要作用。本文对高校三全育人视域下的“四史”教育特 征及实现路径开展了研究。分析了高校“四史”教育与三全 育人模式结合的重要性, 提出了三全育人视域下“四史”教 育具备的特征, 并给出了具体的实现路径。通过本文的研 究, 能够为这种新模式在高校“四史”教育中的广泛开展提 供新的思路。

\section{致谢}

本研究感谢“安徽工程大学党建和思想政治工作研究 课题”（编号：2020ds006) 的支持。

\section{参考文献}

[1] 习近平. 在“不忘初心、牢记使命”主题教育总结大会上的讲 话[N]. 人民日报, 2020-01-09(002).

[2] 习近平. 习近平致信祝贺中国社会科学院中国历史研究院 成立[J]. 中华人民共和国国务院公报, 2019(02): 11.

[3] 门宏悦, 曹军, 刘洋, 张茂仁. 构建研究生思想政治教育 “三全育人”模式 $[\mathrm{J}]$. 沈阳农业大学学报(社会科学版), 2012, 14(02): 185-188.

[4] 牛佳. 马克思“人的全面发展”理论与社会主义核心价值观 [J]. 人民论坛, 2016(22): 106-107.

[5] 易琳. 浅析马克思人的自由全面发展思想 [J]. 延边党校学 报, 2019, 35(04): 29-32.

[6] 熊晓琳，马超林. 马克思 “人的全面发展”思想在当代中国 的发展与实践 $[J]$. 学校党建与思想教育, 2017(10): 4-9.

[7] 陈志华. 高校“三全育人”机制与平台建设研究一以盐城 工学院为例 [J]. 教育现代化, 2017, 4(52): 132-133, 144.

[8] 郑富芝, 梁伟国, 李帆. 以改革提升教育质量——教育部 基础教育二司 2014 年工作思路 [J]. 人民教育, 2014(04): 12-16.

[9] 方涛. 以 “三个结合”开展 “四史”学习教育 [J]. 求 知, 2020(08):30-32.

[10] 戴海容.精准思政视角下新时代高职院校“四史”教育路径论 析[J].学校党建与思想教育,2021(01):72-74.

[11] 王玉.高校思想政治理论课“四史”教学的整体性及其实践路 径[J].思想教育研究,2021(01):123-127.

[12] 张宁, 王伟强. 改革开放以来高校“三全育人”研究综述 $[\mathrm{J}]$. 中国校外教育, 2018(24): 56, 79.

[13] 张文风. 对高校“三全育人”的若干思考 [J]. 学校党建与思 想教育, 2018(04): 60-61, 68 . 
[14] 吴玉程. 新时代高校落实“三全育人”的理论与实践探究[J]. 中国高等教育, 2018(Z2): 35-37.
[15] 左盼盼. 高校党建工作与思想政治教育协同育人模式研究 以“三全育人”机制为构建模式 [J]. 科技经济导刊, 2018, 26(21): 152-153, 155 . 